\title{
Novel sutureless mitral valve implantation method involving a bayonet insertion and release mechanism: A proof of concept study in pigs
}

\author{
Duc-Thang Vu, MD, ${ }^{\mathrm{a}}$ Lian Kah Ti, MD, ${ }^{\mathrm{b}}$ Lay Choo Ong, BEng, MSc, ${ }^{\mathrm{c}}$ Poh Hock Neo, BEng, MSc, ${ }^{\mathrm{c}}$ \\ Chuen Neng Lee, MD, ${ }^{\mathrm{a}}$ and Theo Kofidis, MD, ${ }^{\mathrm{a}}$ Singapore, Republic of Singapore
}

Despite the development of mitral valve repair and percutaneous mitral procedures, mitral valve replacement (MVR) is still the first option for $62 \%$ and $43.2 \%$ to $61 \%$ of patients with mitral regurgitation and mitral stenosis, respectively. ${ }^{1}$ The implantation of a mitral valve prosthesis, however, still involves the time-consuming work of suturing a mitral prosthesis to the mitral annulus. Furthermore, en bloc removal of the degenerated prosthesis, old sutures, and pledgets during reoperative MVR carries the risks of embolism and of injury to the already perforated mitral annulus and relevant structures.

The objectives of the this proof of concept large animal study were to develop a new type of mitral valve implantation mechanism and to prove that the novel technique would remarkably reduce operative and cardiac arrest times, simplifying MVR with comparable efficacy and safety.

\section{MATERIALS AND METHODS \\ Novel Sutureless Mitral Valve}

The novel sutureless mitral valve (Figure 1) is a 2-component device; a hinge ring and the modified prosthetic mitral valve (PMV). The prototypes were fabricated in collaboration with the Biomedical Engineering Group, Nanyang Polytechnic, Singapore, a non-valve-focused facility. All parts were manufactured with rapid-prototyping material (Accura $\mathrm{Si}$ 50; 3D Systems, Inc, Rock Hill, SC).

The hinge ring. This external hinge ring is designed for permanent anchoring to the mitral annulus and functions as the hinge mechanism.

The PMV. The PMV portion could be compatible with any commercially available mitral prosthesis, with the fabric suture ring removed and 2 new indentations added on the outer side of the valve housing ring to engage with the prominences on the hinge ring. In this study, we produced a prototype that mimicked a size 27 conventional mitral bileaflet disk prosthesis.

\footnotetext{
From the Departments of Surgery ${ }^{\mathrm{a}}$ and Anaesthesia, ${ }^{\mathrm{b}}$ Yong Loo Lin School of Medicine, National University of Singapore, Singapore; and the Biomedical Engineering Group, ${ }^{c}$ School of Engineering (Manufacturing), Nanyang Polytechnic, Singapore, Republic of Singapore.

Funded by Proof-of-Concept Grant, Singapore National Research Foundation. Disclosures: Authors have nothing to disclose with regard to commercial support. Received for publication Nov 21, 2011; revisions received Jan 9, 2012; accepted for publication Jan 16, 2012; available ahead of print Feb 13, 2012.

Address for reprints: Theo Kofidis, MD, FAHA, FAMS, Department of Cardiac, Thoracic and Vascular Surgery, National University Health System, Singapore, 1E Lower Kent Ridge Rd, NUHS Tower Block, Level 9, Singapore 119228 (E-mail: surtk@nus.edu.sg).

J Thorac Cardiovasc Surg 2012;143:985-8

$0022-5223 / \$ 36.00$

Copyright (c) 2012 by The American Association for Thoracic Surgery doi:10.1016/j.jtcvs.2012.01.037
}

\section{Animal Model}

Fourteen female Yorkshire pigs, weighing 55 to $75 \mathrm{~kg}$, were divided into control $(n=6)$ and prototype $(n=8)$ groups. Animals in the control group received a size 27 conventional mitral valve prosthesis, whereas the ones in the study group received our prototype. The protocol was approved by the institutional animal care and use committee of the National University of Singapore.

\section{Surgical Technique}

After median sternotomy, cardiopulmonary bypass was established. After aortic crossclamping and institution of cardioplegia, the left atrium was opened and the mitral leaflets were excised, leaving behind a rim of 5 $\mathrm{mm}$. In the control group, the mitral leaflets were excised. Sutures were inserted into the mitral annulus and the mitral prosthesis, followed by knot tying.

In the prototype group, the hinge ring was mounted on the valve holder and introduced into the left ventricle through the mitral annulus to the level at which the pins were just below the annulus. One by one, 12 pins were punched through the mitral annulus. When all 12 pins were in good position, the retainer ring was placed on top of the prototype hinge ring so that the pins could fit into the corresponding holes of the ring in the atrial side. The pins were then bent down against the retainer ring, by doing so pulling the hinge ring and retainer ring closer and thereby clamping the annulus and leaflet tissue in between. The prosthesis was then inserted, twisted, and clicked into position. Anchoring sutures and a valve holder were removed, and leaflet movement was checked. No valve suture was used. The left atrial wall was closed.

The animals were weaned from cardiopulmonary bypass in the usual fashion. The implanted valves were assessed by epicardial echocardiography (GE Vivid-i, 1.5- to 3.6-MHz transducer; GE Healthcare, Chalfont St Giles, UK). The animals were killed 1 hour after termination of cardiopulmonary bypass, and the hearts were harvested for gross examination. One animal was used to test the feasibility of reimplantation of the prosthesis. That animal's heart was put back on cardiopulmonary bypass, after which it was arrested and the left atrium reopened. The implanted PMV was untwisted and taken out. A new PMV was mounted on the valve holder and then inserted into the stable position inside the hinge ring in a twist-and-click fashion, resembling a bayonet mechanism.

\section{RESULTS}

The implantation and aortic crossclamp times of the prototype group were significantly shorter than those of the control group at $26.4 \pm 4.6$ minutes versus $12.4 \pm 3.7 \mathrm{~min}$ utes $(P=.0005)$ and $43.8 \pm 8.5$ minutes versus $29.4 \pm 5.1$ minutes $(P=.014)$, respectively. Implantation time was reduced by 14 minutes in the prototype group (Table 1 ). Electrocardiography did not show any signs of atrioventricular block or ST segment changes. On echocardiography, no paraprosthetic leak was seen. There was a mild central leak arising between the leaflets of the prototype. 
Design of the new valve

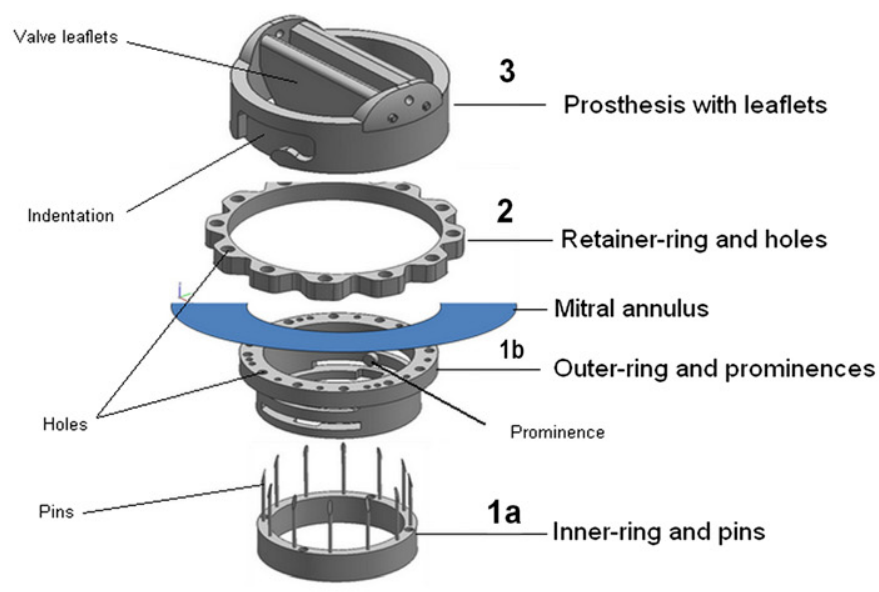

A

C

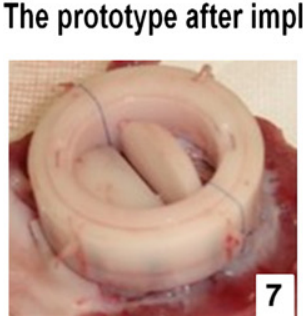

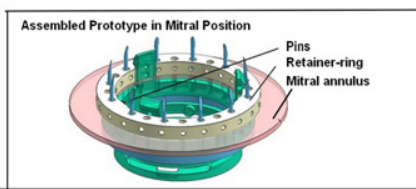

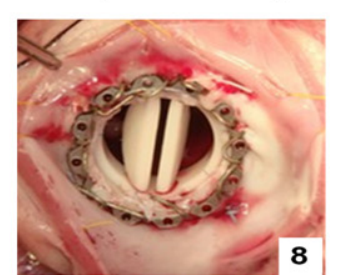

FIGURE 1. Design and prototype of the new valve. A, Design of the new valve. B, The manufactured prototype before implantation. The hinge ring consists of an outer piece carrying an array of pins $(1 a)$ and an inner piece carrying prominences $(1 b)$. The pins go through a series of holes in the inner piece when the 2 pieces are assembled before implantation. The assembled hinge ring with straight and bent pins (1). The retainer ring carries an array of holes to align with the pins from the atrial side of the mitral annulus, after the pins puncture through the real annulus (2). The mitral bileaflet disk prosthetic valve, with 2 indentations for engagement with prominences on the hinge ring (3). The valve holder (4). Prosthetic valve is mounted on the valve holder (5). The pins will be later bent to hold the rings together and attach to the annulus $(6,7)$. The prosthetic valve is inserted into the hinge ring in a twist-and-click fashion, resembling a bayonet mechanism (6). Removal of prosthetic valve can be done simply by twisting and pulling out, in the opposite direction. $\mathrm{C}$, The prototype after implantation in the mitral position: atrial view (7) and ventricular view ( 8 ) of the prototype after implantation. The prototype attached firmly to the mitral annulus. The annular tissue was intact. Note that the healthy valve tissue of the pigs is much thinner and more fragile than that in human beings.

Post mortem gross examination demonstrated that the valve was attached firmly to the annulus. Wherever the pins went through the annulus, the tissue was intact (Figure 1,C). The total crossclamp time of reimplantation

TABLE 1. Surgical time of control and prototype groups

\begin{tabular}{lccc}
\hline \multicolumn{1}{c}{ Time } & $\begin{array}{c}\text { Control } \\
(\mathbf{n = 5})\end{array}$ & $\begin{array}{c}\text { Prototype } \\
(\mathbf{n = 8}=\mathbf{8})\end{array}$ & $\begin{array}{c}\boldsymbol{P} \\
\text { value }\end{array}$ \\
\hline Aortic crossclamp time (min) & $43.8 \pm 8.5$ & $29.4 \pm 5.1$ & .014 \\
Implantation time (min) & $26.4 \pm 4.6$ & $12.4 \pm 3.7$ & .0005 \\
$\begin{array}{l}\text { Time of stitching sutures to } \\
\quad \text { annulus (min) }\end{array}$ & $20.2 \pm 3.5$ & 0 & \\
\hline All data are mean \pm SD. & & & \\
\end{tabular}

was 8 minutes. On post mortem gross examination, we did examine the anatomy of aortic valve, aortic annulus, and circumflex artery, and we found no injury to the mentioned structures.

\section{DISCUSSION}

Most surgeons manage to replace the mitral valve with a crossclamp time ranging from 74 to 93 minutes. ${ }^{2,3}$ The crossclamp time in our prototype group was significantly shorter (29.4 \pm 5.1 minutes), because any time for suturing and tying the knots was omitted (Table 1). It should be noted that the operative duration until opening of the atrium remained the same (data not shown). Where 
the operation is faster is at the point of, and during, valve implantation. Surgical time could be further reduced after a reasonable learning curve. MVR with our device should be feasible with a single shot of cardioplegia. Of note, there was a noticeable extension of the implantation and crossclamp times after the 4th pig (prototype group), as a result of the change in surgeon from an experienced consultant to a resident. The sutureless design might be of benefit in minimally invasive mitral surgery, because it helps avoid the painstaking work of suturing and knot pushing.

Historically, the Magovern-Cromie sutureless valve, a caged-ball prosthesis invented in the era of lower quality of cardiopulmonary bypass in the early 1960s, was the first sutureless valvular prosthesis. Although it helped significantly to shorten bypass time with low rate of paravalvular leak, ${ }^{4,5}$ its absence in current practice could be attributed to the advent of better quality cardiopulmonary bypass, which allows longer and safer crossclamp times, or to the disadvantages of the caged-ball valve design in itself, including a higher incidence of ball malfunction and thromboembolism. ${ }^{4}$ Moreover, this valve was more suitable for the aortic position, but clamping the heart tissue beyond the real annulus by the clawlike pins could cause higher rates of conduction defect. ${ }^{5}$ Even in the current era of advanced cardiopulmonary bypass, there is still abundant evidence that longer cardiac arrest times are associated with increased risks of atrioventricular block ${ }^{6}$ and death, ${ }^{7}$ so a sutureless prosthesis continues to have value.

Our 2-component valve housing apparatus, which consists of a hinge permanently attaching to the annulus and an exchangeable valve carrying the leaflets, is different from the previously described 2-component ValveXchange device $^{8}$ in 2 respects. First, any existing prostheses, either mechanical or bioprosthetic, could be modified to fit into our hinge, and second, the 2 components can be assembled with a bayonetlike twist-and-click mechanism.

Next, our goal is to produce a simple and reliable assembly mechanism. We found that the proposed bayonet mechanism is simple, reliable, durable, and, more importantly, safe. As usual, of course, this assembling mechanism will be subjected to various future modifications. Various sutureless hinge mechanisms are to be found during intellectual property background research, for instance at the United States Patent and Trademark Office. The intellectual property on which this prototype technology was based was generated by the primary investigator (T.K.), who designed this project.

Bending of the pins evenly against the retainer ring and slightly inward could be safe and induce sufficient force for the retainer ring to grasp and hold the annular tissue. This force prevents paravalvular leak or laceration of annular tissue surrounding the pins and reinforces the anchoring of the valve to the annulus, as demonstrated by the lack of paravalvular leakage in echocardiographic and postmortem gross examinations.

Calcified, rheumatic mitral stenosis is one the of major clinical challenges that our proof of concept animal study has not yet addressed. A thick and calcified annulus might cause great difficulty in piercing with the pins, improper alignment of the pins to the holes in the retainer ring, and paravalvular leak. This device might therefore first be used to address degenerative mitral regurgitation and noncalcified mitral stenosis. Calcified valve diseases should be an objective of the next steps of the study, in which further modification of the prototype (eg, a better penetrating pin, a pledgetlike ring layer) and decalcification and implantation techniques can be studied. Further ring attachment mechanisms, such as magnetic force, are being investigated. Surgical experience with both conventional devices and our new device could be useful in deciding which valve is more appropriate in cases in which the potential benefit our new prosthesis in reoperative MVR in the future should be considered. Other options could included the use of the twist-and-click bayonet mechanism only, with a conventional fabric ring used instead of the pins to suture to the mitral annulus.

\section{Limitations of the Study and Perspective}

The rapid-prototyping material used in this study, Accura Si 50, is inferior to the usual materials used in heart valve components (titanium, bicarbon layers, etc). The prototype was therefore thick and less suitable for transprosthetic pressure gradient evaluation, long-term implantation, and handling. The nonsurvival animal model used for this test lacks long-term follow-up data, including chronic changes around the prosthesis and ensuing challenges in reoperative MVR. Finally, our number of subjects was relatively small. These are acceptable limitations in a study that is only a proof of concept.

On the basis of the promising preliminary results, a more specifically experienced valve manufacturer will be engaged to produce the prosthesis for the long-term study. The new design, with a slimmer profile and more durable material, will accommodate both conventional mechanical and biologic valves of different sizes. A survival study will investigate the long-term durability and behavior of the device and will define the amount of coagulation necessary.

Our appreciation and gratitude go to Ms Ng Bok Lan, Mr Goh Si Guim, Ms Patsy Ong, Ms Nantawan Boonkiangwong, Ms Adeline Sim Meng Hui, colleagues in Department of Cardiac, Thoracic and Vascular Surgery, and staff nurses in Cardiothoracic Intensive Care Unit, Advance Surgical Training Center and Nursing Simulation Laboratory in National University Hospital, Singapore, who have contributed immensely to this project. 


\section{References}

1. Iung B, Baron G, Butchart EG, Delahaye F, Gohlke-Bärwolf C, Levang OW, et al. A prospective survey of patients with valvular heart disease in Europe: The Euro Heart Survey on Valvular Heart Disease. Eur Heart J. 2003;24:1231-43.

2. Santini F, Casali G, Viscardi F, Favaro A, Luciani GB, Pentiricci S, et al. The CarboMedics prosthetic heart valve: experience with 1,084 implants. J Heart Valve Dis. 2002;11:121-7.

3. Fiore AC, Barner HB, Swartz MT, McBride LR, Labovitz AJ, Vaca KJ, et al. Mitral valve replacement: randomized trial of St. Jude and Medtronic Hall prostheses. Ann Thorac Surg. 1998;66:707-13.

4. Gott VL, Alejo DE, Cameron DE. Mechanical heart valves: 50 years of evolution. Ann Thorac Surg. 2003;76:S2230-9.
5. Magovern GJ, Liebler GA, Park SB, Burkholder JA, Sakert T, Simpson KA Twenty-five-year review of the Magovern-Cromie sutureless aortic valve. Ann Thorac Surg. 1989;48(3 Suppl):S33-4.

6. Lewis JW Jr, Webb CR, Pickard SD, Lehman J, Jacobsen G. The increased need for a permanent pacemaker after reoperative cardiac surgery. J Thorac Cardiovasc Surg. 1998;116:74-81.

7. Toker ME, Eren E, Guler M, Kirali K, Yanartas M, Balkanay M, et al. Second and third cardiac valve reoperations: factors influencing death and long-term survival. Tex Heart Inst J. 2009;36:557-62.

8. Sun JC, Ghanta RK, Davidson MJ. Highlights from the Transcatheter Cardiovascular Therapeutics Conference 2010: Washington, DC, September 21-25, 2010. J Thorac Cardiovasc Surg. 2011;142:468-71. 